\title{
Single-sex Schooling and Academic Attainment at School and through the Lifecourse
}

\begin{abstract}
This paper examines the impact of single-sex schooling on a range of academic outcomes for a sample of British people born in 1958. In terms of the overall level of qualifications achieved, we find that single-sex schooling is positive for girls at age 16, but neutral for boys, while at later ages, single-sex schooling is neutral for both sexes. However, we find that single-sex schooling is linked to the attainment of qualifications in gender-atypical subject areas for both sexes, not just during the school years, but also later in life.
\end{abstract}

The question of whether single-sex schooling has any impact on academic outcomes remains highly contested. Recent reviews of the evidence have noted the difficulty of comparing like with like, and have commented on the small number of studies that use adequate statistical controls, and the lack of evidence regarding longer term outcomes, such as post-school academic attainment (Mael, et al. 2005; Smithers and Robinson 2006). The current study addresses these issues using longitudinal data collected from a representative British sample of people born in 1958.

Britain and Northern Ireland have a long history of single-sex schooling. However, the progressive school movement in the early 20th century, and Dale's later influential work (Dale 1969; Dale 1971; Dale 1974), both stressed the advantages of boys being educated with girls. Dale's unashamedly partisan volumes argued that boys did better academically in mixed schools, but not at the expense of the girls. He claimed that girls' greater industriousness was communicated to the boys, and boys were spurred on by competition with the girls. Mixed-sex schooling was also more 'natural' and provided protection against homosexuality. "That men and women are complementary is a biological fact. That they also influence each other's conduct- 
from the gift of flowers to the hurling of the kitchen utensils - is an inevitable accompaniment of life in a bisexual world. A family has a father and a mother; lacking one of these each feels incomplete and unsatisfied...So it is with other institutions when they are one-sex - as we know from the homosexual activities in Public School...” (Dale 1969, p.114). [In Britain, the term 'Public School' has historically been applied to élite private boarding schools for boys].

Until the late 1970 's, opposition to co-educational schooling was largely associated with traditional conservative views which made much of the 'distractions' of the opposite sex, and of innate differences between boys and girls (Cowell 1874). However, the liberal consensus regarding the benefits of co-educational schooling was contested by the women's movement in the late 1970s and early 1980s. Some feminists of this period began to re-assert that single-sex education was actually better for girls. For example, Spender's work presented small scale observational and survey evidence that girls got more teacher time and attention and better access to resources in girls-only schools (Spender and Sarah 1980). She and others (Shaw 1976; Stanworth 1983) believed that both the curriculum content and the teaching style in girls' schools were more 'girl-friendly' and helped to raise girls' attainment and selfesteem, and that sexual harassment was an issue in co-educational schools. Nevertheless, there is no one feminist stance on this issue, and the most vocal opposition to single-sex schooling in the US has come from women's groups (Salomone 2004). Some feminist concerns regarding single-sex schooling have derived from the fact that sex-segregation has historically been used to deny opportunities to girls and women. On this view, 'separate but equal' is a myth, and 
feminists should direct their energies to promoting gender equity within the coeducational mainstream (Campbell and Sanders 2002).

In the US, problems with co-educational schooling were raised from another perspective by Coleman (1961), who highlighted the 'cruel jungle of rating and dating' in co-educational schools. Riordan reflects these concerns with the prevalence of anti-learning social norms within many schools, and suggests that single-sex schooling may help to overcome these problems, especially among poor and ethnic minority youth (Riordan 1990; Riordan 2002). However, Riordan argues that the value of single-sex schools is only apparent in those school systems in which they are relatively rare, because, under these circumstances, single-sex schools allow students and parents to make a pro-academic choice, which in turn allows the school to create a strong academic ethos.

Since the early 1990s, the increased academic attainments of girls have led to a moral panic about the 'gender gap' in academic achievement in Britain and elsewhere, and this has also reinvigorated the debate on single-sex schooling (Epstein, et al. 1998). One strand of this debate is a new essentialist literature claiming that boys and girls have fundamentally different brains and correspondingly different 'learning styles' (Gurian, et al. 2001). Despite lacking scholarly credibility, these accounts appeal to 'common-sense' notions of gender, and thus have a popular appeal. Although these new essentialist accounts imply that both boys and girls will benefit from being taught separately, they often stress the benefits for boys, and suggest that single-sex schooling could help close the gender gap in educational attainment. Hoff Summers 
(2000) suggests that it is now boys who are discriminated against in co-educational schools.

At the same time, single-sex classes have been piloted, often as a way of helping boys to achieve academically (Swan 1998; Warrington and Younger 2001). Several studies have assessed the impact of single-sex classes within co-educational schools (Jackson and Smith 2000; Marsh and Rowe 1996; Shapka and Keating 2003). A recent review finds inconclusive results, and argues that much depends on the context in which single-sex classes are introduced (Younger and Warrington 2006). Where single-sex classes are introduced with the aim of raising boys' achievement, girls may be given less attention and fewer resources. In the US, the debate over single-sex schooling has also been revived by the prospect of the revival of publicly supported single-sex provision. Salomone (2006) suggests that this has produced a strange alliance between “...social conservatives touting "hard-wired" differences between girls and boys, political conservatives interested in a free market of parental choice, feminists..., and urban educators and activists..." (p.781).

The issue of subject 'choice' in mixed-sex schools has also been of longstanding concern. Despite girls' increased levels of educational attainment, the underrepresentation of females in mathematics and sciences has been persistent. Disquiet regarding this dates back as far as a Schools' Inspectorate report (DfES 1975) and an Equal Opportunities Commission report (Byrne 1978) stating that both boys and girls in mixed-sex schools made more sex-stereotyped choices than their peers in singlesex schools, despite the greater availability of science facilities in mixed-sex schools than in girls-only schools. Concerns continue to be raised that both boys and girls are 
less likely to pursue sex-atypical subjects in mixed schools, where the pressures to conform to gender stereotypes may be greater than in single-sex schools (Elwood and Gipps 1999; Francis, et al. 2003; Marsh and Yeung 1998). Studies from several countries have examined a range of outcomes including students' orientation towards gendered subject disciplines, their attainment in these disciplines, and the likelihood of them studying these disciplines (Ainley and Daly 2002; Daly 1995; Hannan, et al. 1996; Spielhofer, et al. 2002; Stables 1990; Van de gaer, et al. 2004). There are conflicting findings in this area, and the question of boys' attainment in arts and languages has been relatively neglected.

Of course, the cultural and policy contexts regarding single-sex schools, and the nature of the schools themselves, vary internationally (Baker, et al. 1995). The US context is particularly distinctive, in that title IX legislation had led to the virtual extinction of single-sex public schools, although this has been contested (Salomone 2002), and they have lately experienced some resurgence (Mael 1998). US research has therefore inevitably focussed on private (usually Catholic) schools. This has been seen as raising difficulties of interpretation, as it is unclear to what extent any advantage conferred by these schools is due to their single-sex status per se, and to what extent findings can be generalized to non-Catholic schools (Lee and Bryk 1986; Lee and Marks 1990; Marsh 1989b; Marsh 1991; Riordan 1990). The problem of studies failing to account adequately for differences in the intakes of single-sex and co-educational schools was highlighted by the debate between Lee and Bryk (1986), who found a positive link between single-sex schooling for girls and educational attainment, and Marsh (1989b), who criticised their failure to control for prior academic attainment. 
Much apparently conflicting research evidence continues to be produced internationally regarding the impact of single-sex schooling on levels of academic attainment (Carpenter and Hayden 1987; Caspi 1995; Daly 1996; Elwood and Gipps 1999; Feinstein and Symons 1999; Harker 2000; Mael, et al. 2005; Malacova 2007; Salomone 2003; Smithers and Robinson 2006; Spielhofer, et al. 2004; Steedman 1983a; Woodward, et al. 1999). A recent systematic review of the international English-language research evidence on single-sex schooling (Mael, et al. 2005) states that the overall picture is split between positive findings for single-sex schooling and no differences or null findings, with only one study supporting co-educational schooling. However, a particular concern has been the fact that single-sex schooling is linked to other characteristics of the schools, and of the students attending these schools, and it is not always easy to take this into account adequately (Smithers and Robinson 2006).

Very few studies have examined the longer term outcomes of single-sex and coeducational schooling. Riordan (1990) compared postsecondary test scores for seniors in single-sex and coeducational Catholic high schools in the US, and found results favouring single-sex schools for both boys and girls. Marsh (1989a) examined the rates of participation in education and unemployment two years after high school graduation. Controlling for background variables, there were no statistically significant differences in these outcomes between co-educational and single-sex schools

The pros and cons of mixed and single-sex schooling thus remain a topic of abiding interest, and deeply-held opinions thrive in the absence of sufficient research 
evidence. Consequently policy is being framed and practice instigated which may well be counter-productive.

The dataset used in the current study has important advantages in addressing these questions. First of all, it allows us to address the issue of comparing like with like. Single-sex schooling was quite common for this cohort, rather than being the preserve of a particular social or religious group. In addition, our rich longitudinal data allows us to control for a wide range of characteristics of the children prior to their entry to secondary school. Furthermore, rather than just examining attainment within compulsory schooling, we are able to examine educational attainment at later ages, in a variety of subject disciplines.

\section{Research Questions}

What impact does attending a single-sex as compared to a coeducational school have on the following outcomes?

- At age 16 (1974)

- Overall examination attainment at O-level (national school-leaving exams)

- Attainment in specific subject areas: mathematics and sciences/ English and languages.

- $\quad$ At age 18 (1976) 
O Overall examination attainment at A-level (national exams designed for college-track students)

- Attainment in specific subject areas

- At age 33 (1991)

- The likelihood of having a university degree

- The likelihood of having no qualifications

- The subject area of the highest qualification

- At age $42(2000)$

- Basic skills - literacy and numeracy.

- $\quad$ At age 46 (2004)

- Participation in educational classes

$\circ$ Gaining new qualifications

\section{British Secondary Education in Historical Context}

Historically, state education in Britain was organised along selective lines: pupils were allocated, on the basis of a competitive examination at around age eleven, either to a Grammar school (with a strong academic curriculum preparing students for entry to university), to a Technical school (with a more vocational curriculum) or to a Secondary Modern school (with a much less academic curriculum and preparing students for early entry into the labour market). This was referred to as the 'tripartite' system. In fact, the technical schools never really took off, and catered to fewer than 
$1 \%$ of students, rendering the system effectively bipartite. In 1965 the Labour government mandated a process of abolishing selection at age eleven and of replacing the system of Grammar, Technical and Secondary Modern schools with neighbourhood comprehensive schools on the American model. The process was never fully completed; two local educational authorities (and the whole of Northern Ireland) preserved the selective system. In addition, a number of Grammar schools were also retained by local educational authorities that adopted Comprehensive schools for the bulk of their students, which meant that these 'Comprehensives' were effectively just renamed Secondary Moderns.

The NCDS cohort (described below) experienced an education system that was in transition from the tripartite system to the comprehensive system. Fifty-eight $\%$ of the NCDS respondents attended Comprehensive schools, but $11 \%$ still attended Grammar and Technical schools, 22\% attended Secondary Modern schools, and 6\% attended Private and Direct Grant schools. Private schools are fee-paying schools. Direct Grant schools were fee-paying, but had a proportion of state-funded places. Whereas in the USA, and in most other developed countries, private schools are primarily religious and often highly subsidised (by church or state), British private schools have remained socially and (often) academically exclusive institutions, which are far too expensive for the bulk of the population. Because Britain incorporated most denominational schools within the state sector, its private sector is relatively small. The Grammar schools were far less socially exclusive than the private schools, but somewhat more academically selective. Of course, the Grammar schools were disproportionately middle class, and the secondary-moderns disproportionately working class. Although the aspiration was that comprehensive schools should cater for all, the reality during 
the 1970s was that their social class composition was not very different from that of the secondary moderns.

We exclude from our analyses the small proportion of students who attended schools classified as special or 'other'. We also exclude respondents lacking in information on school sector or school sex at age 16, leaving us with a sample of 12320 . Henceforth, we refer to Grammar and Technical schools as 'Grammar schools', and Private and Direct Grant schools as 'Private schools'.

The proportion of students at single-sex schools ranged from $78 \%$ at private schools to $13 \%$ at Comprehensives. Taken as a whole, a quarter of the cohort attended singlesex schools at age 16. Although single-sex schools were disproportionately represented within the selective sectors, the Comprehensive sector was larger, so if we ask what school sector was attended by students at single-sex schools, the distribution is fairly even: $28 \%$ were at Comprehensive schools, $23 \%$ at Secondary Moderns, $30 \%$ at Grammars, and 19\% at Private schools. This provides an advantage for our analysis, because in school systems where single-sex schooling has become the preserve of a small minority, it is very difficult to compare like with like (Baker, et al. 1995).

In preliminary analyses, the predictors of attendance at a single-sex school have been modelled, and little difference was found in the prior characteristics of students at single-sex and co-educational schools within each school sector (Comprehensive, Grammar, Secondary Modern and Private). The only other important predictor of single-sex schooling is region. This suggests that the danger of spurious results due to 
differences between the pupil populations of single-sex and co-educational schools is minimal, provided that school sector and region are controlled. Crucially, although single-sex schools were disproportionately located within the more socially and academically selective school sectors, within each school sector, single-sex schools were not more socially or academically selective than co-educational schools. This finding may seem surprising, but makes sense in the context of schooling at the time, long before the 'parental choice', school diversity and accountability agendas arrived in Britain. Catchment area rules were strong during this period, and there was therefore relatively little scope for parental choice of school within the state sector. In principle, parents could have moved home in order to be near the school of their choice. Although this is common practice now (Gewirtz, et al. 1995; Gibbons and Machin 2006), the NCDS children started secondary school in 1969, in a very different context. There were no 'league tables' of school examination results at this time, and school quality was not perceived to be very variable within each school sector. In addition, only $46 \%$ of the cohort members were living in owner-occupied properties in 1969, and $42 \%$ were in council housing, and therefore would not have been able to move easily.

In England and Wales, pupils sat public examinations at age 16, the legal minimum school-leaving age. Separate exams were set for different subjects, and the most able students would have sat exams in around eight subjects. There were two sets of public examinations: $\mathrm{O}$ (Ordinary) levels were intended for the most academically able, and CSEs (Certificate of Secondary Education) for the less able. O-level grades ranged from A-G, with A-C grades being deemed a pass. A top grade CSE- grade 1 - was deemed equivalent to a grade $\mathrm{C}$ at $\mathrm{O}-$ level. Public examinations at age 16 have been retained in a 
similar form, although the two tier system ended in 1988, with the introduction of the GCSE exam, which caters for all abilities.

A minority of students in England and Wales stayed on at school from 16 to 18, and studied for 'A' (Advanced) Level exams. The A-level curriculum was highly specialised, and students typically studied for A-levels in only three subjects. A-levels remain the main preparatory qualification for university entrance in England and Wales.

Students in Scotland sat different examinations from those in England and Wales (the Scottish Certificate of Education at age 16, and Highers at age 17). For this reason, we exclude Scottish students from our analyses of school level attainment.

\section{Data and Methods}

The National Child Development Study (NCDS) is a longitudinal study of a single cohort born in Britain in one week in 1958. (Britain includes England, Scotland and Wales, but not Northern Ireland). NCDS has its origins in the Perinatal Mortality Survey, which was designed to examine the social and obstetric factors associated with stillbirth and death in early infancy among British children. This has formed the basis for a continuing, multi-disciplinary longitudinal study, which contains data on many variables relating to health, education, well-being, family formation and labour market participation, among other things. The cohort members have been followed-up 
throughout their lives, and were surveyed for the eighth time in 2004, when they were 46 years old.

The initial sample was designed to be nationally representative of all children in Britain, and achieved a sample size of 17,414 (AUTHOR 2007). By the third follow up, when the children were aged 16, 14,761 respondents remained in the study. Hawkes and Plewis' (2006) examination of attrition and non-response in the NCDS finds few significant predictors of attrition, wave non-response, and missing education data, thus supporting the assumption of ignorable non-response. Neither parental education nor social class were significant predictors of non-response. The distribution of educational qualifications gained by the cohort members by age 33 was closely in line with other data sources (Dale and Egerton 1997).

Previous studies of the effects of single-sex schooling have been criticised for inadequate controls for prior attainment and family background. Given the concentration of single-sex schools in the private and selective sectors, it is important to control for such sources of selectivity. The NCDS gives exceptionally rich information on various aspects of the respondents, their schools and their parents, allowing crucial confounding variables to be controlled. The parents were interviewed at the first three data collection exercises of the study, providing information on social background, parents' age on leaving full-time education, and other characteristics.

Data were also collected directly from the children through tests and questionnaires administered at school at the ages of 7, 11 and 16. Extensive information on 
examination results was collected directly from the schools. From the age of 16 onwards, the respondents themselves were interviewed.

The NCDS cohort took a range of tests at ages 7 and 11, allowing us to condition of prior attainment in an unusually fine-grained way (1980; Steedman 1983b; Steedman 1983c). There are some gender differences in the mean scores (see Table 1). For example, at age 11, boys have a substantively slight, but statistically significant, advantage in mathematics, and girls are somewhat ahead in both verbal and nonverbal reasoning.

\section{TABLE 1}

It should be noted that, although we have both individual-level and school-level data, we are not able to identify whether students attended the same school as other members of the sample. The sample is not clustered, i.e. students are not sampled within schools. Instead, the sample consists of all children born in Britain in the relevant week. It is very likely therefore that many schools would be represented by a single sample member. It is therefore neither possible nor necessary to apply a multilevel statistical model to these data. A further limitation is that, due to the small numbers of ethnic minority individuals included in the NCDS, it is not possible to conduct analyses according to ethnic group.

It is important to acknowledge Steedman's (1983a) analyses of the NCDS pupils' academic attainment at age 16, which compared single-sex and co-educational schools. Steedman's analyses examined the chances of attaining particular 
combinations of subject $\operatorname{passes}^{1}$, whereas we focus here on attainment in sexstereotyped disciplines, and on later outcomes.

In order to control for a range of possible confounding variables, we have modelled academic outcomes using regression analyses. Most of the outcomes we consider are binary, hence we use binary logistic regression. The exception is the number of subject passes. As this is an ordered outcome, we investigated the appropriateness of using ordinal regression. However, the proportional odds assumption was violated, making a partial proportional odds model more appropriate. The partial proportional odds model permits some covariates to be modelled with the assumption of proportional odds, while allowing others to have odds ratios which vary by cut-off point (Lall, et al. 2002). We use gologit2 (Williams 2006).

The key variables included in all models are as follows. These variables comprise 'Model 1' in all regressions.

- School sex

- Pupils'sex

- School sector: this is crucial, as it is linked to school sex.

- Region - data collected at age 16 . This is included as a control variable, as it is a predictor of attending a single-sex school.

- Fathers' social class - age 11. Seven category version of the Hope-Goldthorpe scale. In the case of missing values on this variable (2 278 cases) we imputed the value from information on the father's social class at the two previous sweeps of the study, which left us with 355 cases with missing information on this variable. Missingness on this variable often predicts equally negative or 
even more negative outcomes than even the lowest social class category, therefore it is likely that data is missing 'Not at Random' (Rothon 2007). These cases are treated as a separate category.

- Parental educational level - age at which parent left full-time education, mothers' or fathers' age, whichever is highest. 2657 missing values are treated as a separate category.

- Test scores at age 7 and 11 , as shown in table 1 (transformed into $\mathrm{Z}$ scores). We impute missing values on each of the test scores from the full set of test scores, using the Expectation-Maximization algorithm (Schafer 1997). Early test scores, social class background and parental education are all powerful predictors of educational attainment, and previous studies of singlesex and co-educational schooling have been criticised for omitting such measures.

\section{Analyses}

Our examination of academic attainment at $\mathrm{O}$ - and A-level is limited to schools in England and Wales, since Scotland had different qualifications.

\section{Attainment at 16}

\section{Overall Exam Passes}

The raw figures suggest an enormous advantage for single-sex schools in examination attainment at age 16 in 1974 . We start by examining the chances of getting five or more passes at O-level A-C/ CSE1, because this benchmark, though high, has been historically important in Britain, representing the hurdle students have needed to clear to 
be likely candidates for A-level and subsequent university entrance. $15 \%$ of co-ed boys achieved 5 or more passes at this level, compared with $37 \%$ of single-sex boys. For girls, the gap was even wider: $14 \%$ of co-educated girls achieved 5 or more passes, compared with $42 \%$ of single-sex educated girls. On average, $24 \%$ of girls and $22 \%$ of boys achieved 5 or more passes, so girls were at a slight overall advantage compared to boys in the sample as a whole, but a slight disadvantage in the coeducational sector.

However, these raw differences are extremely misleading, given the concentration of single-sex schools within the private and selective sectors. Once school sector is taken into account, the difference in exam results between single-sex and co-educational schools appears more modest.

\section{FIGURE 1}

Within the comprehensive sector, there was no difference in the proportion of boys at co-ed and boys-only schools gaining 5+ good GCE passes (14\% in both cases). However, while girls at co-ed comprehensives fared slightly worse than their male peers (with $13 \%$ getting 5+ good passes), girls at single-sex comprehensives were substantially more likely to perform at this benchmark (20\%). This corresponds to an odds ratio of 1.7 for girls in single-sex comprehensives compared to girls in co-ed comprehensives.

In table 2, we show the results of a binary logistic regression, where the outcome is gaining five or more A-C passes at O-level, contrasted with getting four passes or 
fewer. We ran separate models for girls and boys, in order to investigate the possibility of gender-specific effects or interactions. In general, the pattern of associations between the background variables and the chances of gaining 5+ A-C grades was similar for both sexes.

\section{TABLE 2}

The students' test scores in reading and mathematics at age 11 were highly predictive of attainment at 16 , alongside the fathers' social class and the parents' age at leaving full-time education. As is well established, children with 'professional' fathers had the highest levels of educational attainment. Students at private and grammar schools were substantially more likely to gain $5+$ good GCE passes, compared to students at Comprehensives, while students at Secondary Moderns were less likely to. The private school advantage was stronger for boys, which may be due to the fact that many of the oldest and most prestigious private schools were boys' schools. Controlling for all of these factors, girls who attended single-sex schools had 1.9 times the odds of gaining 5+ passes than girls at coeducational school - a substantial difference. In contrast, for boys, there was no significant effect of attending a singlesex school.

We tested for interactions between school-sex and school-sector and social class, but these were not statistically significant. However, we found a significant negative interaction between single-sex schooling and test scores at age 11. This is shown in table 2 as SINGLE-SEX*Test age 11. However, in the case of girls the significant interaction found is between single-sex schooling and the reading test score at age 11, 
whereas for boys we found a significant interaction with the mathematics test score at age 11. This may suggest a relative advantage of single-sex schooling for academically weaker students, and a relative disadvantage for academically stronger students. It also suggests that girls who are relatively weak readers and boys who are relatively weak at mathematics gain an advantage from single-sex schooling.

Since the benchmark of five or more A-C passes was only achieved by a minority of this cohort, we also examined attainment at lower levels. Girls were more likely than boys to gain at least one A-C pass (50\% compared to 44\%). However, single-sex schooling was not significantly linked to academic outcomes at this level for either boys or girls. A positive impact of single-sex schooling for girls only becomes apparent at the level of two or more passes (analyses available on request). While this could be interpreted as meaning that single-sex schooling had a greater impact for more able girls, recall that we found a negative interaction between prior attainment and single-sex schooling for girls.

\section{Exam subject passes}

During the 1970s, there were concerns that girls' schools lacked the facilities and staff needed to teach physical sciences. Part of the 'progressive' case for co-education was that gender subject segregation would decrease in co-educational schools, as both sexes would have access to the same curriculum and facilities. On this view, girls should have been more likely to take mathematics and sciences, and boys should be more likely to take English and modern languages, in co-educational rather than single-sex schools. 
Nevertheless, there have been concerns over the years that, instead of promoting attainment in gender-atypical subjects, co-educational schools actually enforce gendered norms of behaviour more powerfully than single-sex schools. On this view, we would expect boys and girls to be more likely to take gender atypical subjects in single-sex than in co-educational schools.

We examined whether single-sex schooling was associated with the likelihood of gaining passes in specific subject disciplines. In general, a higher proportion of girls achieved passes in English and modern languages, while a higher proportion of boys achieved passes in mathematics, physics and chemistry. Thus, these groups of subjects can be seen as gender-typed, with languages being seen as 'female' and 'hard sciences' (excluding biology) being seen as 'male'.

Figure 2 shows the number of exam passes in mathematics, physics and chemistry gained by the subset of boys and girls at co-ed and single-sex schools who gained at least one pass in any subject at O-level/CSE1. Figure 3 shows the number of passes in English, French, and an additional modern language gained by boys and girls at co-ed and single-sex schools. It appears that boys and girls at single-sex schools gained more passes in both of these subject groupings. However, we have to bear in mind that, as well as being highly gendered subject groupings, 'hard' sciences and modern languages are also prestigious subjects, in which students at the selective schools would be expected to gain more passes. Regression analysis controlling for school sector and other factors shows a different picture.

FIGURES 2 AND 3 
Because this paper includes analyses of a large number of outcomes, we present summaries of the findings, rather than showing them in full. We show only the parameters for boys (contrast=girls), girls' school and boys' school (contrast=co-ed). However, the full list of variables listed earlier under 'model 1' is included, as in all the models presented henceforth.

The numbers of subject passes are modelled using a partial proportional odds model. The number of passes in mathematics, physics and chemistry ranges from 0-3. This outcome is modelled in table 3 . The first row contrasts 0 passes with 1, 2 and 3 passes, the second row contrasts 0 and 1 with 2 and 3, and the third row contrasts 0,1 and 2 with 3 . Odds ratios greater than 1 indicate that higher values on the explanatory variable make it more likely that the respondent will be in a higher category of O-level passes than the current one, while odds ratios less than 1 indicate that higher values on the explanatory variable increase the likelihood of being in the current or a lower category.

Table 3 shows that boys were more likely than girls to gain a higher number of science passes. While the size of the effect varies across the rows, it is large and positive for each of them. Girls who attended girls' schools were likely to achieve more science passes than co-educated girls, and the parallel lines assumption was not violated for this variable, hence the estimates are constant across rows (odds ratio=1.4). In the case of boys' schooling, the estimates are less than 1 for each row, but only the second category is statistically significant. Boys at boys' schools were more likely than coeducated boys to achieve 0 or 1 science passes as opposed to 2 or 3 . 


\section{TABLE 3 and 4}

Turning to the model for English and modern languages, shown in table 4, boys gained substantially fewer passes than girls in these subjects. Boys in boys' schools were significantly more likely than coeducated boys to get two or three language passes. For girls in girls' schools, the pattern is more complex, with a positive coefficient for the second row, and a negative one for the third. Girls in single-sex schools were more likely to gain at least one language pass, but less likely to gain two or three.

Overall, the results confirm that girls did better in mathematics and science, and boys did better in languages, at single sex schools. That is to say, co-education was associated with increased gender differentiation in subject-specific attainment.

\section{Attainment at 18}

A minority of students stayed on at school from 16 to 18 , and studied for ' $A$ '

(Advanced) Level exams.14.6\% of boys and $14.3 \%$ of girls gained one or more A-level passes by 1976. Binary logistic regression analysis (shown in table 5, under 'A-level $1+$ ') shows that there was no significant impact of single-sex schooling for either boys or girls. However, there were substantial differences in the subjects that boys and girls passed at A-level at single-sex and co-educational schools. Our analyses regarding Alevel passes and subjects are also summarised in Table 5. As stated above, these summaries just show the parameters for gender and single-sex schooling, although the full set of controls is included in each model.

\section{TABLE 5}




\section{FIGURE 4}

Of those students who gained at least one A-level pass, $42 \%$ of boys and $17 \%$ of girls gained one pass in mathematics, physics or chemistry. $34 \%$ of girls and $15 \%$ of boys gained at least one pass in English or a modern language. Figure 4 shows girls from single-sex schools were more likely than co-educated girls to get at least one A-level in mathematics, physics or chemistry. Boys at single-sex schools were slightly less likely than co-educated boys to get any A-levels in these subjects. Girls from both coeducational and girls' schools had similar chances of getting an A-level in English or a modern language. Boys from boys' schools were more likely than co-ed boys to get an A-level in these subjects.

The pattern shown in these tables is confirmed by the results of binary logistic regression analyses, summarised in Table 5. Boys from boys' schools had 2.2 times the odds of boys at coeducational schools of getting English or a modern language A-level. Girls were significantly more likely (odds ratio $=1.6$ ), and boys significantly less likely (odds ratio $=0.5$ ), to get an A-level in mathematics, physics or chemistry if they had attended a single-sex school.

We add two additional models to these analyses (models 2 and 3 - shown in Table 5). Model 2 includes the number of O-level/CSE1 passes in mathematics, physics and chemistry, and in English and modern languages. This allows us to examine the extent to which differences in academic attainment at $18+$ were based on differences at $16+$, or were above and beyond these initial differences. Model 3 includes students' academic self-concepts in mathematics science and English - i.e. how good they thought they were at these academic subjects - at age 16. In previous work 
(AUTHOR forthcoming) we have shown that self-concept was more gendered in the coeducational schools. Here, we investigate whether self-concept mediated the effect of single-sex schooling on A-level subject specialisation.

The number of A-C passes the student gained in 'hard sciences' at 16+ was highly predictive of the likelihood of gaining a 'hard science' A-level, whereas the number of passes in languages was not a significant predictor of this outcome. In this model, the odds ratio for boys compared to girls is reduced from 7.4 to 3.4. The single-sex effect is reduced to statistical insignificance in this model.

In model 3, self-concept was highly predictive, even having controlled for examination attainment in the previous model. High self-concept in mathematics and science increased the odds of achieving a 'hard science' A-level, whereas high selfconcept in English reduced them. This mediated the male advantage to some extent, though it was still significant. The estimate for boys' only schooling was reduced to insignificance in this model.

Turning to the chances of getting an A-level pass in English or a modern language, the number of A-C passes in English and languages at 16+ was positively linked to the chances of gaining an A-level pass in these subjects, while science A-C passes at 16+ were a negative predictor of achieving an A-level in English or a language. This mediated the effect of being male to some degree, and also reduced the boys' school coefficient to insignificance. 
Model 3 shows the effect of including self-concept in the model. Having above average self-concept in English was a positive predictor of gaining an A-level in English or modern languages, while above-average self-concept in science was a negative predictor. The effect of being male is mediated slightly in this model, but is still highly significant.

So, the link between single-sex schooling and gendered subject attainment at age 18 was mediated by academic attainment and self-concept at age 16 .

\section{Post-school Qualifications}

Henceforth, we use the whole sample, including Scotland.

\section{Qualifications by age 33}

$11 \%$ of the cohort women and $14 \%$ of the men had been awarded a degree by 1991 , when they were aged 33. A quarter of men who had attended boys' schools compared to $11 \%$ of coeducated men, and $21 \%$ of girls' school women compared to $7 \%$ of coeducated women received degrees (see Figure 5). But this apparent advantage of single-sex schooling is in fact entirely due to the association of single-sex and selective schooling, and there is no significant difference once school sector is controlled.

\section{FIGURE 5}

At the opposite end of the spectrum of qualifications, $11 \%$ of the cohort men and $14 \%$ of the women had no qualifications by age 33. Again, an apparent differential in 
favour of single-sex schooling is accounted for by controlling for school sector. Table 6 summarises the results of our analyses of outcomes at age 33 .

\section{TABLE 6}

We went on to investigate the possibility that the subject area of the highest qualification gained was related to single-sex schooling. Because the cell sizes for each individual subject area were small, we did not examine the chances of a qualification in a particular subject area, but instead grouped subjects according to whether they were 'male-dominated', 'female-dominated' or 'integrated', 'integrated disciplines' being defined as those with no more than $60 \%$ of one sex. (Coding frame due to Dale and Egerton (1997).

\section{FIGURE 6}

Figure 6 shows that women who had attended girls' schools were more likely than coeducated women to have male-typed highest qualifications; and men who went to boys' schools were more likely than co-educated men to have female-typed qualifications. Having said this, single-sex schooling by no means eliminates the hugely gendered pattern of subject specialism. More than half of the girls' school women had femaletyped qualifications, and more than half of the boys' school men had male-typed qualifications.

Regression analyses confirm that, other things equal, women were significantly more likely to study male-dominated subjects, and less likely to study female-dominated subjects if they had attended single-sex schools. The increased odds of gaining a femaletyped qualification for men who had attended boys' schools did not quite reach statistical significance $(\mathrm{p}=0.053)$. 
We investigated the possibility that exam passes at $16+$ and self-concept may have influenced the chances of gaining male-dominated and female-dominated qualifications, as we did for A-level subject passes. Model 2 shows that 'hard science' O-levels are a positive predictor, and language O-levels a negative predictor, of attaining maledominated qualifications by age 33 . The differential in odds in favour of men is reduced from 9.0 to 8.0 in this model. However, the relatively high odds of women who had been to single-sex schools, compared to co-educated women, gaining male-dominated qualifications were not reduced in this model.

Model 3 includes self-concept at age 16. Self-concept in mathematics and science were positively linked, and self-concept in English negatively linked, to the likelihood of gaining a male-dominated qualification. The effect of being male is only slightly reduced in this model, and the effect of girls-only schooling is not changed.

Turning to female-dominated qualifications, model 2 shows that having three language passes is positively linked to gaining a female-dominated qualification, while having three 'hard science' passes is negatively linked to this outcome. However, the odds for men compared to women; and for single-sex women compared to co-educated women are not changed in this model. The odds for single-sex men compared to co-educated men actually increase slightly in this model, gaining statistical significance.

Model 3 shows the effect of including self-concept at age 16 in the model. Although self-concept in mathematics, science and English are all significant, and work in the expected directions, this does not mediate the sex effect. The effect of single-sex schooling for girls is marginally mediated in this model. 
Overall then, the association of single-sex schooling with the gender-type of the highest qualifications the cohort members gained by age 33 could not be accounted for by the effects of single-sex schooling on attainment at 16 and on self-concept.

\section{Basic Skills at age 42}

In 2000, the cohort members were asked whether they could read and understand magazine and newspaper text. Only $4 \%$ of men and $3 \%$ of women responded that they could not read these materials, or only with difficulty. This is approximately in line with other estimates of elementary literacy (Parsons and Bynner 2005; Williams, et al. 2003). They were also asked whether they could work out change from $£ 10$. Only $2 \%$ of both men and women responded that they could only do so with difficulty or not at all. This is well below assessments of below basic innumeracy in the national surveys of adult basic skills requiring a battery of different tests (Williams, et al. 2003) ${ }^{2}$. Of course, selfreports of basic skills must be treated with caution, as people have been found to have an 'optimistic bias' in rating their own abilities, and self-assessments are distorted by factors such as gender (Marsh, 1989). However, neither of these outcomes was linked to single-sex schooling.

\section{TABLE 7}

Lifelong learning at age 46 
The 2004 sweep of the survey had a particular focus on questions of lifelong learning, and respondents were asked whether they had attended any work-related training courses, or any courses for interest or leisure during the last four years. They were also asked whether they had gained any vocational or academic qualifications during this period. Women were more likely to have taken courses for leisure or interest (24\% compared to $19 \%$ of men), and men were more likely to have taken courses for work ( $37 \%$ compared to $29 \%$ of women). Women were more likely than men to have gained new qualifications, whether vocational or academic (27\% compared to $19 \%$ of men). However, as Table 7 shows, none of these measures of lifelong learning was related to whether or not the school attended was single-sex.

\section{Conclusions}

This paper has provided a longitudinal analysis of the effects of single-sex schooling on academic outcomes, controlling for students' family background characteristics as well as their prior test scores. Our findings relate to a time when single-sex schooling was widespread, and when most parents had little choice over which type of school their child would attend. Thus, we can be relatively confident that our results are not simply driven by differences in the types of children who attended single-sex and coeducational schools; a difficulty which has dogged previous studies. Our data also allow us to look at longer term outcomes, something which very few previous studies of single-sex schooling have been able to do. An understanding of the educational trajectories of this generation of men and women, who have been tracked into their maturity and middle-age, is relevant for understanding the gendered patterns of their lives, in the labour market and elsewhere. 
Our conclusions can be summarised as follows:

- Girls at single-sex schools were substantially more likely than their coeducated peers to achieve a high level of examination success at age 16, but boys were neither significantly advantaged nor disadvantaged in terms of overall examination attainment by attending single-sex schools.

- There was no significant impact of single-sex schooling on the level of later educational attainments for either sex.

- Single-sex schools were associated with attainment in gender atypical subject areas for both boys and girls.

- Women who had attended single-sex schools were more likely than coeducated women to gain their highest qualification by age 33 in a maledominated field.

The fact that girls performed better at O-level in single-sex schools supports the case made by feminists of the 1970s that mixed schooling disadvantaged girls. However, the advantage of single-sex schooling only emerged at relatively high levels of attainment at 16 . Half of the sample achieved no A-C passes, and the odds of achieving any passes at all were not improved by attending a single-sex school. It is important to remember that schools in 1970s Britain still held very low expectations for the educational attainment of the majority of the population. In this context, it may be that some single-sex girls' schools promoted an ethos of high academic attainment which provided a substantial advantage, but only to a minority of girls. 
The level of qualifications gained post-16 was not linked to single-sex or coeducational schooling for either men or women, and neither were basic skills or lifelong learning in adult life. In the case of the women, this is surprising, as one might have expected the single-sex girls' advantage at 16 to be sustained to some extent. It may be that the advantages of single-sex schooling were strongly linked to the particular context of adolescence and compulsory schooling, with its associated behavioural issues, brutal social hierarchies, and intense peer-group pressures (Coleman 1961). Co-ed girls whose performance at age 16 was lower than it might have been in a single-sex school may have been able to catch up later on. It is also possible that the generally low aspirations for girls' and women's post-compulsory education during the 1970s prevented single-sex school girls from capitalising on their early gains. Although nearly half of graduates born in 1958 had been to single-sex schools (46 per cent versus 22 per cent of the rest), this simply reflected their socially and academically selective nature, not any particular educational benefit of single-sex schooling.

Girls at girls' schools were more likely to gain mathematics and science A-levels, and boys at boys' schools to gain A-levels in English and modern languages, compared with those in co-educational schools. In addition, women who went to girls' schools were more likely than co-educated women to gain post-school qualifications in maledominated disciplines. This confirms the view that single-sex environments can actually reduce the tendency of students to behave according to gender-typical stereotypes or norms. But why should this be? Marsh's 'Big-Fish-Little-Pond' theory may be relevant here. Marsh and Hau (2003) argue that academic self-concept is determined by students' frame of reference, such that students with high attaining peers will be more likely to consider themselves 'below average' than students of the 
same prior ability who are surrounded by lower-attaining peers - the 'Big-Fish-LittlePond' (BFLP) syndrome. In previous work (AUTHOR forthcoming), we found that the gender gap in self-concept in mathematics and sciences and English was stronger in the co-educational sector than in the single-sex schools. However, we also found no substantial differences in average test scores in mathematics and English between boys and girls prior to entry to secondary school. We therefore argued that students may be using as a frame of reference, not only the actual abilities of their peers, but a view of their abilities which is itself influenced by sex-stereotypes. So, a boy who believes that boys are better than girls at mathematics, will be more likely to assume that he is 'above average' in a mixed setting, since he underestimates the girls.

Given the link between academic self-concept and single-sex schooling, we wished to examine whether self-concept at age 16 mediated the impacts of gender and singlesex schooling on the fields of study of post-16 qualifications. Interestingly, the effects of single-sex schooling on subject-specific attainment at A-level were mediated both by subject-specific attainment at O-level, and by academic self-concept at age 16 . This seems to indicate the importance of the impact of single-sex schooling on these early outcomes. However, the effect of single-sex schooling on the chances of gaining male or female dominated post-school qualifications were largely not mediated in this way, leaving a direct effect that could not be explained in our models.

There are of course other possible mechanisms which may promote gender-atypical fields of study within single-sex schools. Several related mechanisms may be at work, at the level of the peer group, the classroom, the teacher and the school. 1. The peer group: As well as the Big-Fish-Little-Pond explanation, a further account that 
operates at the level of the peer group is the view that gendered norms of behaviour are more flexible or less rigidly enforced within single-sex settings. A single-sex environment may make it less likely that students will perceive particular academic subjects as being 'for' a particular sex. While, in a co-educational school, a girl taking physics, for example, would have found herself in a minority in the class, this would not apply in a single-sex environment. A further potential contributing factor is that children may hold more prescriptive stereotypes regarding the opposite sex than regarding their own sex (Guttentag and Bray 1976). 2. Pupil-teacher classroom interactions: While it has been suggested that that boys tend to dominate coeducational mathematics and science lessons, much less attention has been given to girls' and boys' behaviour in co-educational English and modern languages lessons. Neither is it clear to what extent these sorts of classroom interactions actually affect academic attainment or subsequent course-taking. 3. The teacher: The teachers who chose to work in single-sex schools were relatively likely to be of the same sex as the students. It has been suggested that female science teachers may achieve particularly good results with girls, and male language teachers with boys. However, current research findings in this area are very mixed (Carrington, et al. 2008; Dee 2007; Ehrenberg, et al. 1995; Nixon and Robinson 1999; Sokal, et al. 2007). 4. The school: It is possible that some single-sex schools may have had a deliberate ethos of promoting success in gender-atypical subject areas for their students. This would be reflected in the curriculum and in the advice given to students regarding subject options and careers. However, there is no evidence that single-sex schools made gender-atypical subjects more available to their students than coeducational schools in general (Bone 1983), and our own findings also fail to indicate this. Twenty-one percent of the girls in our sample stated, at age 16, that they had never studied science 
- and we found that single-sex schooling was not a significant predictor of this outcome (Author, forthcoming).

What implications does our study have for today's debates? The fact that girls' fared better academically in single-sex than in co-educational schools during the 1970s cannot be taken to imply that this must still be the case. The British birth cohort surveys of 1946, 1958 and 1970 have documented the changing relative educational achievements of males and females, alongside changes in the role of women within the labour market and the wider society (Makepeace, et al. 2003). It is not widely recognised that, in terms of overall educational qualifications at 16 , girls were fractionally ahead of boys even in 1974, when the 1958 cohort were 16 . This is despite the fact that many of the parents and teachers of that generation would not have thought that academic qualifications were as important for girls as they were for boys. Girls' achievement at 16 was in spite of their subordinate status, and boys still achieved higher levels of post-compulsory qualifications. Girls' marginal average advantage at the 5+ A-C benchmark was entirely driven by girls in girls' schools, as co-educated girls were slightly less likely to achieve this benchmark than co-educated boys.

The fact that girls are now outperforming boys in terms of academic attainment at school has been an enormous political issue in countries including Britain, the US and Australia. It is plausible to infer that, in Britain, this gap would be even larger had it not been for the decline in single-sex schooling. Yet it is important to point out that, if we can extrapolate from our findings, an increase in the provision of single-sex 
schooling would have improved girls' academic attainments, but not at the expense of the boys, as boys in boys' schools did just as well as co-educated boys.

Since boys are 'underachieving', it is sometimes inferred that co-educational schools must now be treating boys unfairly (as schools have too many female teachers, and have become 'feminised'). Yet, as outlined above, during the 1970s, girls achieved similar levels of school attainment to boys even within co-educational schools, despite the gender discrimination they faced both within and outside school. We are therefore sceptical of the claim that boys would necessarily now benefit from single-sex schooling in the way that girls did in the past. However, if single-sex schools can help to combat boys' resistance to 'feminine' subject areas such as reading, this could potentially have an impact on boys' general academic attainment.

In Britain, as in the US, social class and ethnicity are more important determinants of overall academic attainment than gender. Policy discourse in Britain has focussed on black boys, and increasingly on working-class white boys, who are now put forward as the most disadvantaged group. However, it is not always recognised that girls' advantage over boys in terms of examination attainment at age 16 operates across social class and ethnic groups. The gender gap in examination attainment in Britain is at least as great for the middle-class as for the working-class. The discourse of male disadvantage ignores the fact that males retain powerful advantages in the labour market and the wider society. Women continue to suffer a penalty in the labour market compared to men with the same level of qualifications. This penalty is lower for graduate women (Makepeace, et al. 2004), although the labour market returns to degrees in maths, science and related subjects remain higher than returns to degrees in 
arts, social sciences and education for both sexes (Conlon and Chevalier 2003). Young women leaving school with no qualifications are the most disadvantaged compared to their male peers (Bynner, et al. 1997; Howieson and Ianelli 2008; Rake 2000). This surely presents girls with greater incentives than boys to achieve academically, yet this is rarely considered as a potential explanation for their relative academic success.

Some commentators have suggested that single-sex schools may help disadvantaged boys, including those from ethnic minorities (Riordan 2002). Our research cannot address the ethnic question, but since we found no effect of single-sex schooling on boys' overall attainment, and no interaction between social class and the effect of single-sex schooling, our research lends no support this view in general terms, although much no doubt depends on the goals and ethos of individual schools.

Nevertheless, the fact that single-sex schooling was neutral, rather than negative, for boys may be seen as surprising. The idea that boys' schools must be particularly difficult environments seems intuitively plausible, given that boys tend to present more disciplinary problems than girls. And this view is supported by research showing that the more males there are in a co-educational class, the worse both sexes fare academically (Lavy and Schlosser 2007). So how did the boys' schools attended by the 1958 cohort manage to achieve very similar academic results to their coeducational counterparts? It is possible that a boys-only environment actually reduced the peer pressure on boys to act-up, or that boys-only schools were particularly effective at dealing with boys' behaviour. This question regarding the potential role of single-sex schooling in overcoming disruptive anti-academic youth 
cultures is central to Riordan's argument (2002), and demands more research at the micro level.

The under-representation of women in mathematics and sciences is an issue that has persisted since the 1970s. There is currently a tendency to see girls' relatively low participation in 'masculine' subjects such as mathematics and sciences, and boys' low participation in 'feminine' subjects such as English and modern languages, as driven simply by personal 'choice' and 'ability', in an unproblematic way. Essentialist views on gender which attribute such observed gender differences to differences in the male and female brain are currently in vogue. Our study shows that the huge gender differentiation in the subject areas of qualifications gained by our cohort members certainly could not be accounted for by the very small gender differences observed in their prior test scores.

Hubbard and Datnow (2002) point out that single-sex schooling needs to be driven by an agenda of gender equity for both boys and girls. Of course, we can say the same for co-educational schooling. Our findings have implications for co-educational as well as single-sex schools. In both of these contexts, there is a need to move beyond seeing girls' versus boys' achievement as a zero sum game, where female success must imply male failure. Broader gender issues should not be forgotten: notably, the issue of the ways in which both girls and boys may be trammelled by sex-stereotypes during their school years, which set them on divergent pathways in their later lives and careers. The fact that coeducation has exacerbated the gendered nature of students' attainments, not just at school, but in terms of their post-school 
qualifications, suggests that gendered norms regarding education are not immutable, and can be influenced by the context of schooling.

The policy debate on single-sex schools in the US has centred on the legality of providing single-sex provision within the public sector, and whether single-sex provision could help certain categories of students. But we would suggest that the impact of single-sex schools on neighbouring co-educational schools is also an issue that should not be neglected, especially in the context of the education quasi-market. While parents see girls' schools as having advantages ranging from protecting girls from early sexual activity to allowing them to be more assertive, boys' schools are often seen as too tough and macho (Heather 2002). In England, Local Education Authorities that have maintained single-sex provision for girls despite a lack of parental demand for single-sex provision for boys have been faced with a serious gender imbalance in their coeducational schools (some schools are 70\% male). Policymakers in the US and elsewhere who are considering expanding single-sex provision need to be aware of these potential unintended consequences.

The effects of single-sex schooling are contingent on national and historical factors (Ewing 2006). As such, we would welcome more international longitudinal research evidence, especially relating to the longer-term outcomes of single-sex schooling. Large-scale longitudinal studies are invaluable in allowing us to assess the short and long-term outcomes of single-sex and co-educational schooling. However, in order to fully engage with some of the theoretical rationales that have been put forward, both in support of and in opposition to single-sex schooling, it would also be useful to see 
more mixed-methods research bringing together insights into the micro-processes of schooling alongside information on academic and other outcomes.

\section{NOTES}

1. Steedman (1983) presents a summary of the outcome of logistic regressions where the dependent variables at age 16 are gaining exam passes in: 1 . both English and mathematics; 2. both a science and French; 3. all of mathematics, English, French and a science. This modelling strategy examines subject combinations which could be seen as 'gender balanced' rather than gender stereotyped. These analyses were published as a report to the Equal Opportunities Commission.

2. $5 \%$ were reported to be at entry level 1 in numeracy, and $16 \%$ at level 2 by the 'Skills for Life' survey. These tests are more demanding than simply working out change from $£ 10$, so are not strictly comparable to the self-reports used by NCDS.

\section{BIBLIOGRAPHY}

Ainley, J. and Daly, P. (2002) Participation in Science Courses in the Final Year of High School in Australia: The influences of single-sex and coeducational schools in A. Datnow and L. Hubbard (eds) Gender in Policy and Practice: perspectives on single-sex and co-educational schooling (pp., London: RoutledgeFalmer.

Baker, D. B., Riordan, C. and Schaub, M. 1995. The effects of sex-grouped schooling on achievement: the role of national context. Comparative Education Review, 39: 468-482.

Bone, A. (1983) Girls and girl-only schools: a review of the evidence.Manchester: Equal Opportunities Commission.

Bynner, J., Morphy, L. and Parsons, S. (1997) Women, Employment and Skills in H. Metcalf (ed) Half Our Future (pp. 66-97). London: Policy Studies Institute. 
Byrne, E. (1978) Women and Education.London: Tavistock Publications.

Campbell, P. B. and Sanders, J. (2002) Challenging the System: Assumptions and data behind the push for single-sex schooling in A. Datnow and L. Hubbard (eds) Gender in Policy and Practice: Perspectives on Single-Sex and Coeducational Schooling (pp. 31-46). New York: Routledge Falmer.

Carpenter, P. and Hayden, M. 1987. Girls' academic achievements: Single-sex versus coeducational schools in Australia. Sociology of Education, 60: 156-167.

Carrington, B., Tymms, P. and Merrell, C. 2008. Role models, school improvement and the 'gender gap' - do men bring out the best in boys and women the best in girls? British Educational Research Journal, 34(3): 315-327.

Caspi, A. (1995) Puberty and the gender organization of schools: how biology and social context shape the adolescent experience in L. J. Crockett and A. C. Crouter (eds) Pathways through adolescence: Individual development in relation to social contexts (pp., Mahwah NJ: Erlbaum.

Coleman, J. S. (1961) The Adolescent Society.Glencoe, Illinois: The Free Press.

Conlon, G. and Chevalier, A. (2003) Does it Pay to Attend a Prestigious University?, London: Centre for the Economics of Education

Cowell, H. 1874. Sex in Mind and Education: A Commentary. Blackwood's Edinburgh Magazine, 115.

Dale, A. and Egerton, M. (1997) Highly educated women: Evidence from the national child development study.London: HMSO.

Dale, R. (1969) Mixed or Single-sex School? Volume I.London: Routledge and Kegan Paul.

— (1971) Mixed or Single-sex School? Volume II.London: Routledge and Kegan Paul.

— (1974) Mixed or Single-sex School? Volume III.London: Routledge and Kegan Paul.

Daly, P. 1995. Science course participation and science achievement in single-sex and co-educational schools. Evaluation and Research in Education, 9(2): 91-98.

- 1996. The effects of single-sex and co-educational secondary schooling on girls' achievement. Research Papers in Education, 11(3): 289-306.

Dee, T. S. 2007. Teachers and the gender gaps in student achievement. Journal of Human Resources, 42(3): 528-554.

DfES (1975) Curricular Differences for Boys and Girls, London: HMSO

Ehrenberg, R. G., Goldhaber, D. D. and Brewer, D. J. 1995. Do Teachers' Race, Gender, and Ethnicity Matter? Evidence from the National Educational Longitudinal Study of 1988. Industrial and Labor Relations Review, 48(3): 547-561.

Elwood, J. and Gipps, C. (1999) Review of Recent Research on the Achievement of Girls in Single-sex Schools.London: Institute of Education.

Epstein, D., Elwood, J., Hey, V. and Maw, J. (eds) (1998) Failing Boys?, Buckingham: Open University Press.

Ewing, E. T. 2006. The Repudiation of Single-Sex Education: Boys' Schools in the Soviet Union, 1943-1954. American Educational Research Journal, 43(4): 621-650.

Feinstein, L. and Symons, J. 1999. Attainment in secondary school. Oxford Economic Papers, 51: 300-321.

Francis, B., Hutchings, M., Archer, L. and Melling, L. 2003. Subject Choice and Occupational Aspirations among Pupils at Girls' Schools. Pedagogy, Culture and Society, 11(3): 425-442. 
Gewirtz, S., Ball, S. J. and Bowe, R. (1995) Markets, Choice and Equity in Education.Buckingham: Open University Press.

Gibbons, S. and Machin, S. 2006. Paying for primary schools: Supply constraints, popularity or congestion. The Economic Journal, 116(510): 77-92.

Gurian, G., Henley, P. and Trueman, T. (2001) Boys and Girls Learn Differently!San Francisco: Jossey-Bass.

Guttentag, M. and Bray, H. (1976) Undoing Sex Stereotypes: research and resources for educators. New York: McGraw Hill.

Hannan, D. F., Smyth, E., McCullagh, J., O' Leary, R. and McMahon, D. (1996) Coeducation and Gender Equality.Dublin: Oak Tree Press.

Harker, R. 2000. Achievement, gender and the single-sex/ coed debate. British Journal of Sociology of Education, 21: 203-218.

Hawkes, D. and Plewis, I. 2006. Modelling Non-Response in the National Child Development Study. Journal of the Royal Statistical Society, A., 169: 479-491.

Heather, B. (2002) Constructions of Gender in Parents' Choice of a Single-sex School for their Daughters in A. Datnow and L. Hubbard (eds) Gender in Policy and Practice: Perspectives on Single-Sex and Co-educational Schooling (pp. 304322). New York: Routledge Falmer.

Hoff Sommers, C. (2000) The War Against Boys: How misguided feminism is harming our young men. New York: Simon \& Schuster.

Howieson, C. and Ianelli, C. 2008. The effects of low attainment on young people's outcomes at age 22-23 in Scotland. British Educational Research Journal, 34(2): 269-290.

Hubbard, L. and Datnow, A. (2002) Are Single-sex Schools Sustainble in the Public Sector in A. Datnow and L. Hubbard (eds) Gender in Policy and Practice: Perspectives on single-sex and co-educational schooling (pp. 109-132). New York: Routledge Falmer.

Jackson, C. and Smith, I. D. 2000. Poles apart? An exploration of single-sex and mixed-sex educational environments in Australia and England. Educational Studies, 26: 375-391.

Lall, R., Campbell, M. M., Walters, S. J. and Morgan, K. 2002. A review of ordinal regression models applied on health-related quality of life assessments. Statistical Methods in Medical Research, 11: 49-67.

Lavy, V. and Schlosser, A. 2007. Mechanisms and Impacts of Gender Peer Effects at School. NBER Working Paper, 13292.

Lee, V. E. and Bryk, A. S. 1986. Effects of single-sex secondary schools on student achievement and attitudes. Journal of Educational Psychology, 78: 381-395.

Lee, V. E. and Marks, H. M. 1990. Sustained Effects of the Single-Sex SecondarySchool Experience on Attitudes, Behaviors, and Values in College. Journal of Educational Psychology, 82(3): 578-592.

Mael, F., Alonso, A., Gibson, D., Rogers, K. and Smith, M. (2005) Single-Sex Versus Coeducational Schooling: A Systematic Review.Policy and Program Studies Service: US Department of Education.

Mael, F. A. 1998. Single-Sex and Coeducational Schooling: Relationships to Socioemotional and Academic Development. Review of Educational Research, 68(2): 101-129.

Makepeace, G., Dolton, P. and Joshi, H. 2004. Gender earnings differentials across individuals over time in British Cohort Studies 1991 and 2000. International Journal of Manpower, 25(3/4): 251-263. 
Makepeace, G., Dolton, P., Woods, L., Joshi, H. and Galinda-Rueda, F. (2003) From School to the Labour Market in E. Ferri, J. Bynner and M. Wadsworth (eds) Changing Britain Changing Lives (pp. 29-70). London: Bedford Way Papers. Malacova, E. 2007. Effect of single-sex education on progress in GCSE. Oxford Review of Education, 33(2): 233-259.

Marsh, H. W. 1989a. Effects of Attending Single-Sex and Coeducational HighSchools on Achievement, Attitudes, Behaviors, and Sex-Differences. Journal of Educational Psychology, 81(1): 70-85.

- 1989b. Effects of Single-Sex and Coeducational Schools - a Response to Lee and Bryk. Journal of Educational Psychology, 81(4): 651-653.

- 1991. Public, Catholic Single-Sex, and Catholic Coeducational High-Schools Their Effects on Achievement, Affect, and Behaviors. American Journal of Education, 99(3): 320-356.

Marsh, H. W. and Hau, K. T. 2003. Big-fish-little-pond effect on academic selfconcept - A cross-cultural (26-country) test of the negative effects of academically selective schools. American Psychologist, 58(5): 364-376.

Marsh, H. W. and Rowe, K. J. 1996. The effects of single-sex and mixed-sex mathematics classes within a coeducational school: A reanalysis and comment. Australian Journal of Education, 40(2): 147-161.

Marsh, H. W. and Yeung, A. S. 1998. Longitudinal structural equation models of academic self-concept and achievement: Gender differences in the development of math and English constructs. American Educational Research Journal, 35(4): 705-738.

Nixon, L. A. and Robinson, M. D. 1999. The educational attainment of young women: Role model effects of female high school faculty. Demography, 36(2): 185-194.

Parsons, S. and Bynner, J. 2005. Measuring Basic Skills for Longitudinal Study: the design and development of instruments for use with cohort members in the age 34 follow-up in the British Cohort Study ( BCS70) Literacy and Numeracy Studies, 14(2): 7-30.

Rake, K. (ed) (2000) Women's Incomes over the Lifetime, London: The Cabinet Office.

Riordan, C. (1990) Girls and boys in school: Together or separate?New York: Teachers College Press.

- (2002) What do we know about the effects of single-sex schools in the private sector? Implications for private schools. in A. Datnow and L. Hubbard (eds) Gender in Policy and Practice: Perspectives on single-sex and co-educational schooling (pp. 10-30). London: Routledge Falmer.

Rothon, C. 2007. Can achievement differentials be explained by social class alone?: An examination of minority ethnic educational performance in England and Wales at the end of compulsory schooling. Ethnicities, 7(3): 306-322.

Salomone, R. C. (2002) The Legality of Single-sex Education in the United States: Sometimes "Equal" means "Different" in A. Datnow and L. Hubbard (eds) Gender in Policy and Practice: Perspectives on single-sex and co-educational schooling (pp. 47-72). New York: Routledge Falmer.

- (2003) Same, Different, Equal: Rethinking Single-Sex Schooling. New Haven: Yale University Press.

— 2004. Feminist Voices in the Debate Over Single-sex Schooling: Finding common ground. Michigan Journal of Gender and Law, 11: 63-95. 
- 2006. Single-sex Programs: Resolving the research conundrum. Teachers College Record, 108(4): 778-802.

Schafer, J. L. (1997) Analysis of Incomplete Multivariate Data.London: Chapman and Hall.

Shapka, J. D. and Keating, D. P. 2003. Effects of a girls-only curriculum during adolescence: Performance, persistence, and engagement in mathematics and science. American Educational Research Journal, 40(4): 929-960.

Shaw, J. (1976) Finishing School: some implications of sex-segregated education in D. L. Barker and S. Allen (eds) Sexual Divisions and Society: process and change (pp., London: Tavistock.

Smithers, A. and Robinson, P. (2006) The Paradox of Single-sex and Co-educational Schooling Centre for Education and Employment Research: University of Buckingham

Sokal, L., Katz, H., Chaszewski, L. and Wojcik, C. 2007. Good-bye, Mr. Chips: Male teacher shortages and boys' reading achievement. Sex Roles, 56(9-10): 651659.

Spender, D. and Sarah, E. (eds) (1980) Learning to Lose: sexism and education, London: Women's Press.

Spielhofer, T., Benton, T. and Schagen, S. 2004. A study of the effects of school size and single-sex education in English schools. Research Papers in Education, 19(2): 133-159.

Spielhofer, T., O'Donnell, L., Benton, T., Schagen, S. and Schagen, I. (2002) The impact of school size and single-sex education on performance. Vol. LGA Research Report volume 33Slough: NFER.

Stables, A. 1990. Differences between Pupils from Mixed and Single-Sex Schools in their Enjoyment of School Subjects and in their Attitudes to Science and to School. Educational Review, 42(3): 221-230.

Stanworth, M. (1983) Gender and Schooling: a study of sexual divisions in the classroom.London: Hutchinson.

Steedman, J. (1980) Progress in Secondary Schools.London: National Children's Bureau.

- (1983a) Examination Results in Mixed and Single Sex Schools: Findings from the National Child Development Study.Manchester: Equal Opportunities Commission.

- (1983b) Examination Results in Selective and Non-Selective Schools.London: National Children's Bureau.

- (1983c) Examination Results in Selective and Non-selective Schools, Volume 2 Appendices.London: National Children's Bureau.

Swan, B. (1998) Teaching boys and girls in separate classes at Shenfield High School in K. Bleach (ed) Raising Boys' Achievement in Schools (pp. 157-172). Stokeon-Trent: Trentham Books.

Van de gaer, E., Pustjens, H., Van Damme, J. and De Munter, A. 2004. Effects of single-sex versus co-educational classes and schools on gender differences in progress in language and mathematics achievement. British Journal of Sociology of Education, 25(3): 307-322.

Warrington, M. and Younger, M. 2001. Single-sex classes and equal opportunities for girls and boys: perspectives through time from a mixed comprehensive school in England. Oxford Review of Education, 27(3): 339-356. 
Williams, J., Clemens, S., Oleinikova, K. and Tarvin, K. 2003. The Skills for Life Survey: a national needs and impact survey of literacy, numeracy and ICT skills. DFES Research Report, 490.

Williams, R. A. 2006. Generalized Ordered Logit/Partial Proportional Odds Models for Ordinal Dependent Variables. The Stata Journal, 6(1): 58-82.

Woodward, L. J., Fergusson, D. M. and Horwood, L. J. 1999. Effects of single-sex and coeducational secondary schooling on children's academic achievement. Australian Journal of Education, 43: 142-156.

Younger, M. and Warrington, M. 2006. Would Harry and Hermione have done Better in Single-Sex Classes: A review of single-sex teaching in co-educational schools in the United Kingdom. American Educational Research Journal, 43(4): 579-620. 